\title{
Estudo correlacional entre interesses profissionais e vivências acadêmicas no Ensino Superior
}

\author{
Ana Paula Porto Noronha \\ Denise da Fonseca Martins \\ Marina Gasparoto do Amaral Gurgel \\ Rodolfo Augusto Matteo Ambiel
}

Resumo

O construto interesse profissional é um dos avaliados quando da realização de processos de Orientação Profissional, embora ainda existam lacunas em sua definição e poucas pesquisas sobre o construto com estudantes universitários e sobre sua relação com sucesso acadêmico. 0 presente estudo teve como objetivo analisar as relações entre interesses profissionais e vivências acadêmicas de estudantes universitários nos primeiros e últimos semestres de dois cursos (Administração e Direito). Participaram 159 estudantes universitários, com idade entre 17 e 51 anos. Os instrumentos utilizados foram a Escala de Aconselhamento Profissional (EAP) e o Questionário de Vivências Acadêmicas - reduzido (QVA-r). Os resultados apontaram diferença de média significativa entre os cursos, nos dois instrumentos, sendo que apenas o QVA-r se diferenciou com relação aos semestres. Correlações positivas e significativas entre a preferência por atividades burocráticas e das ciências humanas e sociais com as vivências nos âmbitos da carreira e do estudo foram encontradas.

Palavras-chave: Avaliação Psicológica, interesses, estudantes universitários, orientação profissional.

\section{Exploratory study between vocational interests and academic existences in Higher Education}

\begin{abstract}
The vocational interest is one of the appraised constructs when accomplished to the vocational guidance process, although it is possible to confirm that there are gaps in its definition, and a small number of researches investigating it in the college students and their relations to academic success. The present research had as objective analyzing the relations between vocational interests and academic existences of college students, in the first and last semesters of two courses (Administration and Advocacy). The participants were 159 college students, between 17 and 51 years old. The instruments applied were "Escala de Aconselhamento Profissional" (EAP) and "Questionário de Vivências Acadêmicas" (QVA-r). The results showed a significant mean difference among the instruments regarding to the course, and only QVA-r showed differences between the students of first and last semesters. Positive and significant correlations between bureaucratic and social/humanistic sciences activities with career and study existences were found.
\end{abstract}

Keywords: Psychological Assessment, interests, college students, vocational guidance.

\section{Estudio de exploración entre intereses profesionales y vivencias académicas en la enseñanza superior}

\section{Resumen}

El concepto Interés Profesional es uno de los evaluados cuando se realizan procesos de Orientación Profesional, aunque existan vacíos en su definición y pocas investigaciones sobre este concepto con estudiantes universitarios y acerca de su relación con el éxito académico. El presente estudio tuvo como objetivo analizar las relaciones entre intereses profesionales y vivencias académicas de estudiantes universitarios en los primeros y últimos semestres de dos facultades (Administración y Derecho). Participaron 159 estudiantes universitarios, con edades entre 17 y 51 años. Los instrumentos utilizados fueron la Escala de Asesoramiento Profesional (EAP) y el Cuestionario de Vivencias Académicas - reducido (CVA-r). Los resultados indicaron diferencia de promedio significativa entre las facultades, en los dos instrumentos, siendo que, sólo el CVA-r se diferenció con relación a los semestres. Correlaciones positivas y significativas entre la preferencia por actividades burocráticas y de las ciencias humanas y sociales con las vivencias en los ámbitos de carrera y del estudio fueron encontradas.

Palabras-clave: Evalución psicológica, interes,estudiantes universitarios, orientación profesional. 


\section{Introdução}

A Orientação Profissional (OP) no Brasil ganhou espaço nas últimas décadas, mais especialmente a partir dos anos 90, com a ampliação de suas possibilidades de atuação como, por exemplo, o desenvolvimento de carreira. A pesquisa de Melo-Silva (1999) a respeito do levantamento de publicações disponíveis em bases de dados no período de 1950 a 2003 revelou que houve aumento no número de pesquisas e o maior predomínio dos artigos teóricos, em detrimento das demais modalidades analisadas. Tais resultados puderam ser parcialmente corroborados pela investigação de Noronha e Ambiel (2006). Os últimos investigaram a mesma base de dados, mas usando palavras-chave diferentes da primeira autora; os achados confirmaram o maior número de trabalhos teóricos, além de chamar a atenção para um número razoável de trabalhos que se destinaram a investigar a qualidade de instrumentos psicológicos. Dos recursos avaliativos mais citados, as técnicas se destacaram, vindo, em seguida, os testes de interesses.

Nesse sentido, no que se refere aos construtos investigados quando do processo de OP, os interesses profissionais merecem destaque. Nesse particular, tanto no Brasil, quanto no exterior, pode-se afirmar que não há consenso quanto à melhor definição do construto interesse. Assim, como nas demais áreas da psicologia, são encontradas muitas concepções distintas e algumas antagônicas (Mattiazzi, 1977).

Savickas (1995) tem sido uma referência importante, sobretudo na literatura norte-americana. Para ele, interesses podem ser compreendidos como padrões de gostos, desgostos e respostas indiferentes. O autor agrupa as teorias em três conjuntos, sendo que o primeiro reúne as concepções embasadas na teoria da aprendizagem, de tal modo que os indivíduos aprendem a gostar das atividades que fazem bem. Lent, Hackett e Brown (1994) são representantes deste grupo e defendem que os indivíduos estabelecem os padrões de aceitação ou rejeição de estímulos ocupacionais por meio da experimentação, da observação do outro ou por meio dos feedbacks recebidos.

No segundo grupo, encontram-se as abordagens que envolvem personalidade e motivação e concebem interesses como se estes estivessem a serviço do desenvolvimento da personalidade. Carter (1940) e Bordin (1943), ambos citados por Savickas (1995), enquadram-se no grupo, sendo que o primeiro autor defendia que os interesses promoviam a integração da personalidade, enquanto o segundo os considerava como a expressão do autoconceito ocupacional. Ainda pode-se incluir Holland (1963) e sua teoria tipológica, cuja concepção versa sobre a associação entre interesses, personalidade e ambientes vocacionais.

Por fim, no último grupo estão as teorias que enfatizam o papel social. Tyler (1951) faz uso de uma metáfora na qual a imagem de uma ponte uniria o papel social ao papel individual. $\mathrm{O}$ interesse seria este conjunto e a aceitação ou rejeição do papel social geraria o gosto ou o desgosto pela atividade. Sob essa perspectiva, os interesses ajudariam na manutenção da integridade do indivíduo, por favorecer a prática de ajustamento às condições ambientais, em um processo de máximo ajustamento e de "autocompletamento".

No Brasil, o estudo dos interesses profissionais ainda é incipiente e parece estar mais relacionado com estudantes de ensino médio (Melo-Silva, Noce \& Andrade, 2003; Okino \& cols., 2003; Welter, 2007). Desta forma, vale ressaltar a pesquisa de Noronha, Santos e Sisto (2007) que construíram a Escala de Aconselhamento Profissional (EAP), que visa avaliar as preferências por atividades profissionais, estudando uma amostra universitária.

Esta escala foi aplicada em seu processo de validação em 762 estudantes universitários (59\% do sexo feminino; idades entre 17 e 73 anos, média de 24,14, DP=7,14) de 12 cursos, a saber: Administração, Direito, Educação Artística, Educação Física, Engenharia, Fisioterapia, Jornalismo, Medicina, Pedagogia, Psicologia, Turismo e Veterinária. Para se avaliar a estrutura interna dos itens, foi feita uma análise fatorial, que indicou uma configuração de sete dimensões, denominadas Ciências Exatas, Artes e Comunicação, Ciências Biológicas e da Saúde, Ciências Agrárias e Ambientais, Atividades Burocráticas, Ciências Humanas e Sociais Aplicadas e Entretenimento.

Além dessa evidência de validade, Noronha e cols. (2007) avaliaram os resultados a partir de um critério externo. Para tanto, buscou-se averiguar em que nível as dimensões encontradas se ajustariam às carreiras universitárias, sendo comparadas as médias dos participantes obtidas em cada dimensão com os cursos frequentados. Assim, essa análise indicou que o curso que obteve a maior média na dimensão Ciências Exatas foi Engenharia $(44,88)$, enquanto que, na dimensão 2, Artes e Comunicação, foi Educação Física $(38,54)$ o curso detentor da maior média. Medicina $(35,54)$ e Fisioterapia $(33,32)$ foram as que obtiveram maiores médias na dimensão Ciências biológicas e da saúde. A dimensão 4, Ciências agrárias e ambientais, indicou Veterinária (38) e Turismo (41) com as maiores médias; Administração $(31,21)$ foi o curso que obteve maior média na dimensão 5 , Atividades Burocráticas. A dimensão 6, Ciências Humanas e Sociais aplicadas, destacou o curso de Pedagogia $(27,32)$ com a maior média e Turismo $(22,23)$ foi o curso que obteve maior média na dimensão 7, Entretenimento.

Esses resultados foram avaliados pelos autores como evidências de validade de critério externo, uma vez que cada dimensão se mostrou capaz de distinguir os cursos cujas atividades típicas são afins com os itens componentes de tais dimensões. Vale ressaltar, porém, que o EAP tem como premissa o fato de que as pessoas podem preferir atividades não típicas apenas de sua própria profissão ou curso, o que embasa a avaliação dos indivíduos por meio de 'perfis de preferência'.

Com relação à precisão, foi analisada a consistência interna das dimensões por três métodos. Em relação ao modelo Rasch, os índices para os itens variaram entre 0,970,99 e para as pessoas, entre $0,76-0,88$. No que se refere 
à Teoria Clássica dos Testes, os valores alfa ficaram entre 0,79-0,94 e os de Spearman-Brown e Guttman, entre 0,750,91 .

Em sua dissertação de mestrado, Sartori (2007) correlacionou as dimensões da EAP com a tipologia vocacional e de personalidade do Self Direct Search (SDS; Holland, 1963), a saber: Realista, Investigativo, Artístico, Social, Empreendedor e Convencional. Participaram da pesquisa 131 estudantes do Ensino Médio, com idades entre 15 e 19 anos, de escolas particulares do interior de São Paulo, sendo que as análises de variância entre sexo e séries não indicaram diferenças significativas. Foram também realizadas correlações entre as dimensões do EAP e a sessão Atividades do SDS. De forma geral, pôde-se observar que as correlações foram teoricamente coerentes como, por exemplo, entre a dimensão Ciências Exatas e os tipos Realista, Investigativo e Convencional; dimensão Ciências Biológicas e da Saúde com os tipos Investigativo e Social; e Atividades Burocráticas com Convencional, Realista e Empreendedor.

Noronha e Ambiel (no prelo) correlacionaram as dimensões do EAP com o SDS em 122 estudantes universitários das áreas de Educação Artística, Psicologia e Medicina Veterinária, com idades entre 17 e 73 anos. Ao se analisar os tipos predominantes em cada curso, Educação Artística obteve média alta nos tipos Artístico e Social; Psicologia pontuou mais em Social e Investigativo; e Veterinária, em Empreendedor e Social. Os resultados parecem estar de acordo com as características dos cursos, principalmente no que se refere aos dois primeiros.

Além disso, correlações foram feitas, sendo que a relação teórica entre os tipos do SDS e alguns itens do EAP pôde ser constatada na amostra estudada. Dentre elas, vale destacar as relações positivas entre o tipo Artístico com os itens 'Recuperar obras e objetos de arte', 'Coordenar a apresentação de um espetáculo de dança' e 'Desenhar'; do tipo Social com os itens 'Estudar o passado humano em seus múltiplos aspectos', 'Estudar a origem do homem e da cultura', 'Responsabilizar-se pela direção teatral', 'Ensaiar artista para um espetáculo' e 'Escrever e revisar textos'; e, por fim, do tipo 'Empreendedor' com os itens 'Cuidar de princípios e normas relativos à arrecadação de impostos, taxas e obrigações tributárias', 'Divulgar e vender softwares', 'Conduzir relações entre empresa e empregado' e 'Projetar robôs e sistemas digitais para fábricas'.

Os estudos nessa área têm indicado que os interesses profissionais são importantes no sucesso acadêmico, embora outros aspectos devam também ser investigados. De acordo com Vendramini e cols. (2004), é crescente a preocupação de órgãos governamentais e agências de fomento com relação à adaptação dos universitários ao nível superior de ensino, considerando que tal situação tende a se refletir no nível de evasão e no desempenho acadêmico. Os autores afirmam ainda que as instituições devem ocuparse igualmente com a formação técnica e pessoal dos estudantes, compreendendo que, no período universitário, o estudante tende a vivenciar períodos de crescimento, sucesso e satisfação, mas também de frustração, fracassos e insatisfação.

Nesse sentido, Cunha e Carrilho (2005) estudaram as relações entre vivências acadêmicas e rendimento acadêmico em 100 estudantes de primeiro ano de Engenharia Militar, com idade entre 16 e 24 anos. Para avaliar as vivências, foi empregado o Questionário de Vivências Acadêmicas (QVA). Em acréscimo, os autores utilizaram as médias dos alunos em três disciplinas consideradas como fundamentais para a formação em Engenharia, a saber: Álgebra Linear, Física e Cálculo. A análise das correlações indicou que as médias em 'Física' se correlacionaram positivamente com as subescalas 'Bem Estar Físico' e 'Gestão do Tempo' do QVA. Já as médias de 'Cálculo' se mostraram positivamente correlacionadas com as subescalas 'Bases de conhecimento para o curso', 'Bem-estar físico', 'Bem-estar psicológico' e 'Ansiedade na realização de exames'. Por fim, as subescalas 'Bases de conhecimento para o curso', 'Bem-estar físico', 'Bem-estar psicológico', 'Gestão dos recursos econômicos', 'Autoconfiança', 'Percepção pessoal de competência cognitiva' e 'Ansiedade na realização de exames' correlacionaram-se com as médias de 'Álgebra Linear'. Dessa forma, os autores concluíram que os alunos com percepções mais acuradas de suas vivências nas dimensões pessoal e acadêmica tendem a ter também melhor rendimento acadêmico.

Comparar as expectativas acadêmicas e a adaptação no primeiro ano de uma universidade portuguesa foi o objetivo de Soares e Almeida (2002). Para tanto, os autores aplicaram em 703 estudantes, de 16 cursos de graduação, um Questionário de Expectativas Acadêmicas (QEA) no início e no final do ano letivo e o QVA no início do segundo semestre do mesmo ano. Os autores procederam a um cálculo da discrepância dos escores das duas aplicações do QEA e formaram quatro grupos. O primeiro foi composto pelos 'alunos surpreendidos', cuja realização no primeiro ano foi superior ao esperado. O segundo grupo ficou formado pelos 'alunos realistas', que realizaram no primeiro ano o que já esperavam. O terceiro grupo foi composto por alunos moderadamente desiludidos e o quarto, por alunos desiludidos, sendo que, em ambos, as realizações ficaram aquém de suas expectativas, com variação de intensidade.

Os resultados foram analisados visando diferenciar os grupos quanto à percepção de sua vivência acadêmica e pôde-se perceber que os alunos surpreendidos e realistas, nas suas expectativas quanto ao relacionamento com os colegas e investimento nas atividades do curso, diferenciaram-se dos demais, apresentando melhores indicadores de gestão de tempo, métodos de estudo, desenvolvimento vocacional, adaptação à instituição e envolvimento em atividades extracurriculares. Ainda, os alunos realistas tenderam a apresentar melhores níveis de bem-estar psicológico, se comparados com o grupo dos alunos mais desiludidos.

Com vistas a examinar a adequação do QVA ao contexto brasileiro, Santos, Noronha, Amaro e Villar (2005) realizaram um estudo da consistência interna do instrumento, contando com a participação de 357 estudantes da área de 
humanas de uma instituição particular de ensino superior do Estado de São Paulo, com idades entre 17 e 57 anos. A fim de se atingir o objetivo do estudo, os autores realizaram o cálculo dos índices de fidedignidade, por meio do coeficiente alfa de Cronbach.

Os resultados indicaram que ocorreram variações entre os coeficientes obtidos entre as amostras brasileira e portuguesa, entretanto, as diferenças não foram significativas. As variações encontradas referem-se às subescalas: Envolvimento em atividades extracurriculares $(0,56)$, Desenvolvimento de carreira $(0,78)$, Bases de conhecimento para o curso $(0,72)$, Gestão de recursos econômicos $(0,77)$, Autonomia pessoal $(0,70)$, Relacionamento com colegas $(0,82)$, Autoconfiança $(0,76)$, Bem-estar físico $(0,75)$, Métodos de estudo $(0,73)$, Relacionamento com professores $(0,76)$, Bem-estar psicológico $(0,86)$ e Relacionamento com a família $(0,81)$, nas quais apresentaram coeficientes inferiores de precisão entre os alunos brasileiros com relação aos coeficientes verificados no estudo realizado em Portugal.

No que diz respeito às subescalas Gestão do tempo $(0,75)$, Adaptação à instituição $(0,76)$, Percepção pessoal de competência $(0,76)$ e Ansiedade na avaliação $(0,79)$, os coeficientes obtidos na amostra brasileira foram superiores quando comparados aos estudantes portugueses. Os resultados encontrados sugerem um bom índice de consistência interna de cada subescala, situados acima de 0,70, com exceção da subescala 'Envolvimento em atividades extracurriculares', que apresentou menor consistência $(0,56)$.

O estudo de Almeida, Soares e Ferreira (2002) objetivou apresentar os procedimentos de construção e validação de uma versão reduzida do Questionário de Vivências Acadêmicas (QVA-r). A versão original contava com 170 itens, distribuídos em 17 subescalas, e apresentava dificuldades de aplicação principalmente relativas ao tempo, segundo os autores. Foram participantes desse estudo 1889 estudantes do primeiro ano de uma universidade portuguesa, sendo que a maioria $(59,1 \%)$ era mulher.

Os autores realizaram uma análise fatorial de segunda ordem, obtendo uma solução de cinco dimensões. A primeira, intitulada Dimensão Pessoal, agrupou itens que originalmente pertenciam às subescalas 'Bem-estar psicológico', 'Bem-estar físico', 'Autoconfiança', 'Autonomia' e 'Ansiedade nas situações de avaliação', com alfa de 0,87. A segunda dimensão (Interpessoal) agrupou itens das subescalas 'Relacionamentos com colegas' e 'Envolvimento em atividades extracurriculares', que apresentou alfa de 0,86 . A 'Dimensão Vocacional' abarcou itens relativos à 'Adaptação ao curso' e ao 'Desenvolvimento de carreira', tendo mostrado alta consistência interna, com alfa de 0,91. A quarta dimensão, intitulada 'Ensino-Aprendizagem', formouse a partir das subescalas 'Métodos de estudo' e 'Gestão do tempo', com alfa de 0,82. Por fim, a 'Dimensão Institucional' reuniu oito itens relativos à 'Adaptação à instituição', apresentando consistência interna de 0,71.

Almeida e cols. (2002) concluíram o trabalho afirmando que o QVA-r, que ficou com 60 itens, apresenta boas qualidades psicométricas, sendo que poderá ser utilizado como estratégia de screening no planejamento de ações que visem melhorar a adaptação dos estudantes ao ensino superior. Ainda assim, afirmaram que o uso do instrumento completo (170 itens) pode ser aconselhável em situações em que as informações precisem ser conhecidas em seus pormenores.

Granado (2004) buscou evidências de validade e precisão para o QVA-r em uma amostra de estudantes universitários brasileiros. Para tanto, o autor investigou as vivências acadêmicas de 626 ingressantes em duas universidades brasileiras, com idades entre 17 e 58 anos $(M=22,01 ; D P=5,2)$.

Umaanálise fatorial exploratóriaindicouapossibilidade da extração de cinco fatores, além da necessidade de mudança de alguns itens de dimensão a partir do que Almeida e cols. (2002) haviam sugerido no estudo original. Além disso, cinco itens que mostraram cargas fatoriais abaixo de 0,30 foram excluídos dessa versão. Dessa forma, o instrumento estudado em amostra brasileira ficou com um total de 55 itens, constituintes das dimensões Carreira, Pessoal, Interpessoal, Estudo e Institucional.

Uma outra evidência de validade foi obtida a partir da correlação entre o QVA-r e as notas dos estudantes. Observou-se que os estudantes que tinham como média semestral até 5,9 tiveram escores significativamente menores no QVA-r do que o grupo com notas semestrais médias acima de 8,0. Quanto à precisão, o método de correlação entre as duas metades foi usado, com coeficiente de 0,80 , atestandose, portanto, características psicométricas do questionário em uma amostra brasileira.

Tendo em vista a importância da compreensão das variáveis implicadas no desenvolvimento acadêmico para os processos de OP e aconselhamento de carreira, o objetivo dessa pesquisa foi, a título de estudo exploratório, analisar as correlações entre vivências acadêmicas e interesses profissionais de estudantes universitários no início e no final dos cursos. Além disso, buscou-se também avaliar as diferenças de médias entre os cursos, bem como entre os grupos ingressantes e concluintes.

\section{Método}

\section{Participantes}

Participaram da pesquisa 159 estudantes universitários, sendo $46,3 \%$ do sexo feminino e $53,7 \%$ do masculino. As idades variaram entre 17 a 51 anos, com média de 24,35 e desvio padrão de 6,08 . Foram avaliados estudantes de uma universidade particular do interior de São Paulo, contando com a participação de dois cursos, Administração (51,2\% alunos) e Direito (48,8\% alunos). Quanto aos semestres, $54,3 \%$ dos alunos estavam matriculados no $1^{\circ}$ semestre de ambos os cursos, $22,2 \%$ matriculados no $8^{\circ}$ semestre do curso de Administração e $23,5 \%$ matriculados no $10^{\circ}$ semestre do curso de Direito. 


\section{Instrumentos}

Foram utilizados dois instrumentos nessa pesquisa, a Escala de Aconselhamento Profissional e o Questionário de Vivência Acadêmica, descritos a seguir.

\section{Escala de Aconselhamento Profissional - EAP}

AEAP foi construído por Noronha e cols. (2007) e avalia as preferências por atividades profissionais. Ele consiste em uma escala de autorrelato do tipo Likert de cinco pontos e possui 61 itens que se distribuem em sete dimensões, a saber: Ciências Exatas, Artes e Comunicação, Ciências Biológicas e da Saúde, Ciências Agrárias e Ambientais, Atividades Burocráticas, Ciências Humanas e Sociais Aplicadas e Entretenimento. O participante deve escolher, entre as opções de 1 a 5 , a intensidade com que gostaria de realizar as atividades. O tempo médio para aplicação é de 15 minutos. Os estudos das qualidades psicométricas do instrumento foram relatados na introdução.

\section{Questionário de Vivência Acadêmica - QVA}

O QVA tem como objetivo identificar as percepções e experiências de estudantes no que se refere à compreensão do processo de integração acadêmica. O instrumento foi desenvolvido em Portugal, por Leandro Almeida e Joaquim Ferreira, em 1997. Em sua versão original, o questionário é composto por 170 itens, em escala do tipo Likert de cinco pontos, variando de 1 (nada a ver comigo) até 5 (tudo a ver comigo), sendo divididos em 17 subescalas (Santos $\&$ cols., 2005).

Na presente pesquisa, foi utilizada a versão reduzida do Questionário de Vivências Acadêmicas, adaptada no
Brasil (Granado, 2004). Essa versão é composta por 55 itens, divididos nas dimensões: Carreira (12 itens), Pessoal (15 itens), Interpessoal (13 itens), Estudo (11 itens) e Institucional (7 itens). Os estudos psicométricos foram relatados na introdução.

\section{Procedimento}

Este projeto foi submetido e aprovado pelo Comitê de Ética de uma instituição particular de ensino superior. Após a assinatura do Termo de Consentimento Livre e Esclarecido, procedeu-se à aplicação dos instrumentos. A coleta de dados se deu de forma coletiva, sendo realizada simultaneamente pelos autores nos cursos de Administração e Direito. O primeiro instrumento aplicado foi o EAP e, logo após, o QVA. O tempo médio para aplicação de ambos foi de 30 minutos.

\section{Resultados e Discussão}

A Tabela 1 mostra as estatísticas descritivas das dimensões dos instrumentos. Nota-se que a dimensão 'Atividades Burocráticas' alcançou a maior média, enquanto que a dimensão 'Ciências Biológicas e da Saúde', a menor. Com relação ao QVA-r, as maiores médias foram nas dimensões 'Carreira' e 'Interpessoal', enquanto que a dimensão 'Institucional' revelou a menor média.

As diferenças de média entre sexos foram analisadas e são apresentadas na Tabela 2. Com relação ao EAP, verifica-se que apenas na dimensão 'Ciências Exatas' os sexos diferenciaram-se significativamente, com maior média para os homens. Já nas dimensões do QVA-r, as mulheres obtiveram médias mais altas na dimensão 'Estudo',

Tabela 1. Estatística descritiva dos instrumentos EAP e QVA-r

\begin{tabular}{lccccc}
\hline \multicolumn{1}{c}{ EAP } & $N$ & Mínimo & Máximo & Média & DP \\
\hline Ciências Exatas & 154 & 14 & 66 & 32,90 & 11,68 \\
Artes e Comunicação & 149 & 14 & 69 & 34,68 & 10,80 \\
Ciências Biológicas e da Saúde & 154 & 9 & 45 & 21,05 & 8,75 \\
Ciências Agrárias e Ambientais & 152 & 16 & 65 & 38,28 & 9,97 \\
Atividades Burocráticas & 150 & 18 & 61 & 42,59 & 8,43 \\
Ciências Humanas e Sociais & 147 & 17 & 50 & 31,83 & 6,67 \\
Entretenimento & 155 & 6 & 30 & 16,98 & 6,12 \\
& & & & & \\
Pessoal & 147 & 32 & 69 & 50,66 & 8,03 \\
Interpessoal & 150 & 23 & 60 & 47,89 & 7,84 \\
Carreira & 151 & 26 & 60 & 48,40 & 6,96 \\
Estudo & 154 & 21 & 45 & 33,61 & 5,34 \\
Institucional & 150 & 14 & 40 & 31,04 & 4,62 \\
\hline
\end{tabular}

Fonte: Elaboração dos autores. 
Tabela 2. Diferenças de média e teste $t$ entre sexos

\begin{tabular}{|c|c|c|c|c|c|c|}
\hline$E A P$ & Sexo & $N$ & Média & $D P$ & $t$ & $p$ \\
\hline \multirow[t]{2}{*}{ Ciências Exatas } & M & 71 & 35,85 & 13,01 & 2,97 & 0,003 \\
\hline & $\mathrm{F}$ & 83 & 30,38 & 9,81 & & \\
\hline \multirow[t]{2}{*}{ Artes e Comunicação } & M & 70 & 35,12 & 11,94 & 0,47 & 0,638 \\
\hline & $\mathrm{F}$ & 79 & 34,29 & 9,74 & & \\
\hline \multirow[t]{2}{*}{ Ciências Biológicas e da Saúde } & M & 72 & 20,20 & 8,85 & $-1,13$ & 0,260 \\
\hline & $\mathrm{F}$ & 82 & 21,80 & 8,64 & & \\
\hline \multirow[t]{2}{*}{ Ciências Agrárias e Ambientais } & M & 72 & 37,11 & 11,07 & $-1,37$ & 0,170 \\
\hline & $\mathrm{F}$ & 80 & 39,33 & 8,81 & & \\
\hline \multirow[t]{2}{*}{ Atividades Burocráticas } & M & 69 & 42,75 & 8,76 & 0,21 & 0,831 \\
\hline & $\mathrm{F}$ & 81 & 42,45 & 8,20 & & \\
\hline \multirow[t]{2}{*}{ Ciências Humanas e Sociais } & M & 67 & 31,26 & 7,28 & $-0,94$ & 0,347 \\
\hline & $\mathrm{F}$ & 80 & 32,31 & 6,12 & & \\
\hline \multirow[t]{2}{*}{ Entretenimento } & M & 70 & 17,10 & 6,55 & 0,22 & 0,826 \\
\hline & $\mathrm{F}$ & 85 & 16,88 & 5,77 & & \\
\hline \multicolumn{7}{|l|}{ QVA-r } \\
\hline \multirow[t]{2}{*}{ Pessoal } & M & 64 & 50,82 & 8,42 & 0,21 & 0,831 \\
\hline & $\mathrm{F}$ & 83 & 50,54 & 7,76 & & \\
\hline \multirow[t]{2}{*}{ Interpessoal } & M & 71 & 47,11 & 7,79 & $-1,15$ & 0,249 \\
\hline & $F$ & 79 & 48,59 & 7,87 & & \\
\hline \multirow[t]{2}{*}{ Carreira } & M & 70 & 47,35 & 7,85 & $-1,72$ & 0,086 \\
\hline & $F$ & 81 & 49,30 & 6,00 & & \\
\hline \multirow[t]{2}{*}{ Estudo } & $M$ & 72 & 32,72 & 5,78 & $-1,96$ & 0,051 \\
\hline & $F$ & 82 & 34,40 & 4,82 & & \\
\hline \multirow[t]{2}{*}{ Institucional } & $M$ & 68 & 30,79 & 4,25 & $-0,59$ & 0,555 \\
\hline & $\mathrm{F}$ & 82 & 31,24 & 4,92 & & \\
\hline
\end{tabular}

Fonte: Elaboração dos autores.

diferenciando significativamente da média masculina.

Visando analisar as possíveis diferenças existentes entre faixas etárias, obedeceu-se à organização das médias pelos quartis. Assim, foram compostos três grupos, a saber: abaixo de 19 anos (quartil 25), entre 19 e 26 (acima de 25 até 75) e acima de 26 anos (acima do quartil 75). A partir dessa formação, realizou-se análise de variância (ANOVA), que não indicou diferenciação significativa entre os grupos no EAP, mas sugeriu uma diferença significativa na dimensão 'Carreira' do QVA-r $[F(159,2)=5,624 ; p=0,004]$. A prova de Tukey (Tabela 3) mostrou que o grupo acima de 26 anos obteve a maior média, tendo se diferenciado principalmente do grupo etário intermediário.

ATabela 4 apresenta as médias obtidas nas dimensões dos dois instrumentos de acordo com os cursos, bem como as análises de diferença de média. Com relação ao EAP, observa-se que apenas a dimensão 'Artes e Comunicação' não se diferenciou significativamente. Nas demais, podese perceber que os sujeitos estudantes de Administração

Tabela 3. Prova de Tukey para os grupos etários, na dimensão Carreira do QVA-r

\begin{tabular}{llcr}
\hline Idade & $N$ & 1 & 2 \\
\hline $19-26$ & 72 & 46,54 & \\
$<19$ & 39 & 49,46 & 49,46 \\
$>26$ & 37 & & 50,89 \\
Sig. & & 0,10 & 0,58 \\
\hline
\end{tabular}

Fonte: Elaboração dos autores. 
Tabela 4. Diferença de média e teste $t$ dos cursos para EAP e QVA-r

\begin{tabular}{|c|c|c|c|c|c|c|}
\hline$E A P$ & Curso & $N$ & Média & $D P$ & $t$ & $p$ \\
\hline \multirow[t]{2}{*}{ Ciências Exatas } & Adm. & 80 & 34,86 & 11,82 & 2,18 & 0,031 \\
\hline & Dir. & 74 & 30,79 & 11,22 & & \\
\hline \multirow[t]{2}{*}{ Artes e Comunicação } & Adm. & 78 & 33,20 & 10,30 & $-1,76$ & 0,080 \\
\hline & Dir. & 71 & 36,30 & 11,17 & & \\
\hline \multirow[t]{2}{*}{ Ciências Biológicas e da Saúde } & Adm. & 80 & 19,11 & 7,93 & $-2,94$ & 0,004 \\
\hline & Dir. & 74 & 23,16 & 9,15 & & \\
\hline \multirow[t]{2}{*}{ Ciências Agrárias e Ambientais } & Adm. & 79 & 35,89 & 9,35 & $-3,15$ & 0,002 \\
\hline & Dir. & 73 & 40,86 & 10,05 & & \\
\hline \multirow[t]{2}{*}{ Atividades Burocráticas } & Adm. & 76 & 44,71 & 8,16 & 3,21 & 0,002 \\
\hline & Dir. & 74 & 40,41 & 8,19 & & \\
\hline \multirow[t]{2}{*}{ Ciências Humanas e Sociais } & Adm. & 76 & 30,28 & 7,06 & $-2,98$ & 0,003 \\
\hline & Dir. & 71 & 33,49 & 5,83 & & \\
\hline \multirow[t]{2}{*}{ Entretenimento } & Adm. & 80 & 18,72 & 5,61 & 3,82 & 0,000 \\
\hline & Dir. & 75 & 15,12 & 6,12 & & \\
\hline \multirow[t]{2}{*}{ Pessoal } & Adm. & 75 & 50,72 & 8,36 & 0,08 & 0,935 \\
\hline & Dir. & 72 & 50,61 & 7,72 & & \\
\hline \multirow[t]{2}{*}{ Interpessoal } & Adm. & 79 & 46,68 & 8,25 & $-2,01$ & 0,046 \\
\hline & Dir. & 71 & 49,23 & 7,18 & & \\
\hline \multirow[t]{2}{*}{ Carreira } & Adm. & 77 & 46,76 & 7,54 & $-3,02$ & 0,003 \\
\hline & Dir. & 74 & 50,10 & 5,89 & & \\
\hline \multirow[t]{2}{*}{ Estudo } & Adm & 81 & 33,39 & 5,34 & $-0,54$ & 0,589 \\
\hline & Dir. & 73 & 33,86 & 5,37 & & \\
\hline \multirow[t]{2}{*}{ Institucional } & Adm. & 77 & 32,66 & 3,92 & 4,71 & 0,000 \\
\hline & Dir. & 73 & 29,32 & 4,71 & & \\
\hline
\end{tabular}

Fonte: Elaboração dos autores.

obtiveram maiores médias em 'Ciências Exatas', 'Atividades Burocráticas' e 'Entretenimento', enquanto que os estudantes de Direito destacaram-se nas dimensões 'Ciências Biológicas e da Saúde', 'Ciências Agrárias e Ambientais' e 'Ciências Humanas e Sociais Aplicadas'.

No que toca ao QVA-r, três das cinco dimensões se diferenciaram significativamente quando considerados os cursos. Dessas, percebe-se que os estudantes de Direito obtiveram maiores médias nas dimensões 'Interpessoal' e 'Carreira', enquanto que estudantes de Administração destacaram-se em 'Institucional'.

Foram analisadas as diferenças de média nos dois instrumentos com relação ao semestre cursado (Tabelas 5 e 6). As preferências por atividades profissionais dos estudantes dos dois cursos não se diferenciaram em nenhuma dimensão da EAP, comparando-se estudantes em início e fim de curso. No QVA-r, as dimensões 'Carreira', 'Estudo' e
'Institucional' mostraram-se significativamente diferenciadas para os estudantes de Administração, sempre com maiores médias para os cursantes do primeiro semestre.

Com relação aos estudantes de Direito, as dimensões 'Interpessoal' e 'Institucional' diferenciaram-se significativamente, sendo que, na primeira, a média foi maior para os estudantes de décimo semestre e, na segunda, para os estudantes de primeiro semestre. Vale ressaltar que os níveis de significância da dimensão 'Estudo' do QVA-r, do curso de Administração, e das dimensões 'Interpessoal' e 'Institucional', do curso de Direito, foram marginais.

As correlações entre as dimensões do EAP e QVA-r são descritas na Tabela 7, sendo que as significativas serão destacadas a seguir. Pode-se observar que a dimensão 'Artes e Comunicação' correlacionou-se positivamente com 'Interpessoal', enquanto que 'Ciências Biológicas e da Saúde' mostrou-se negativamente correlacionada com 'Institucional'. 
Tabela 5. Diferença de média e teste $t$ do curso Administração EAP e QVA-r

\begin{tabular}{|c|c|c|c|c|c|c|}
\hline$E A P$ & Semestre & $N$ & Média & $D P$ & $t$ & $p$ \\
\hline \multirow[t]{2}{*}{ Ciências Exatas } & 1 & 45 & 33,88 & 11,50 & $-0,83$ & 0,407 \\
\hline & 8 & 35 & 36,11 & 12,29 & & \\
\hline \multirow[t]{2}{*}{ Artes e Comunicação } & 1 & 44 & 31,68 & 10,03 & $-1,49$ & 0,138 \\
\hline & 8 & 34 & 35,17 & 10,46 & & \\
\hline \multirow[t]{2}{*}{ Ciências Biológicas e da Saúde } & 1 & 45 & 18,26 & 7,24 & $-1,08$ & 0,282 \\
\hline & 8 & 35 & 20,20 & 8,72 & & \\
\hline \multirow[t]{2}{*}{ Ciências Agrárias e Ambientais } & 1 & 44 & 35,68 & 8,34 & $-0,23$ & 0,819 \\
\hline & 8 & 35 & 36,17 & 10,60 & & \\
\hline \multirow[t]{2}{*}{ Atividades Burocráticas } & 1 & 42 & 45,73 & 7,74 & 1,22 & 0,225 \\
\hline & 8 & 34 & 43,44 & 8,61 & & \\
\hline \multirow[t]{2}{*}{ Ciências Humanas e Sociais } & 1 & 42 & 30,95 & 6,75 & 0,90 & 0,367 \\
\hline & 8 & 34 & 29,47 & 7,45 & & \\
\hline \multirow[t]{2}{*}{ Entretenimento } & 1 & 46 & 19,06 & 5,70 & 0,62 & 0,532 \\
\hline & 8 & 34 & 18,26 & 5,53 & & \\
\hline \multicolumn{7}{|l|}{ QVA-r } \\
\hline \multirow[t]{2}{*}{ Pessoal } & 1 & 44 & 51,72 & 7,37 & 1,24 & 0,217 \\
\hline & 8 & 31 & 49,29 & 9,54 & & \\
\hline \multirow[t]{2}{*}{ Interpessoal } & 1 & 46 & 46,73 & 7,21 & 0,07 & 0,944 \\
\hline & 8 & 33 & 46,60 & 9,63 & & \\
\hline \multirow[t]{2}{*}{ Carreira } & 1 & 45 & 48,28 & 6,92 & 2,14 & 0,035 \\
\hline & 8 & 32 & 44,62 & 7,97 & & \\
\hline \multirow[t]{2}{*}{ Estudo } & 1 & 47 & 34,34 & 5,17 & 1,90 & 0,061 \\
\hline & 8 & 34 & 32,08 & 5,37 & & \\
\hline \multirow[t]{2}{*}{ Institucional } & 1 & 44 & 33,59 & 3,42 & 2,47 & 0,016 \\
\hline & 8 & 33 & 31,42 & 4,25 & & \\
\hline
\end{tabular}

Fonte: Elaboração dos autores.

A dimensão 'Ciências Agrárias e Ambientais' correlacionouse positivamente com 'Interpessoal' e negativamente com 'Institucional'.

Ainda, as dimensões 'Atividades Burocráticas' e 'Ciências Humanas e Sociais Aplicadas' correlacionaram-se positivamente com as dimensões 'Carreiras' e 'Estudo' do QVA-r, embora com intensidades e níveis de significância diferentes. Por fim, a dimensão 'Entretenimento' do EAP correlacionou-se positivamente com 'Institucional' do QVA-r.

O presente estudo caracterizou-se como exploratório e teve como objetivo analisar as correlações entre interesses profissionais e vivências acadêmicas de estudantes universitários ingressantes e concluintes, bem como as diferenças de médias entre sexo, idade, cursos e semestres cursados. Nessa direção, os resultados encontrados visam auxiliar na compreensão de fenômenos relativos ao ensino universitário, principalmente no que se refere à orientação de carreira e planejamento acadêmico.

Observou-se que, diferentemente do apontado por Sartori (2007), houve diferença significativa entre sexos na dimensão 'Ciências Exatas' do EAP. Vale ressaltar que o estudo de Sartori (2007) foi realizado com estudantes de ensino médio, ou seja, uma amostra distinta da usada nesse estudo. Ainda sobre as diferenças entre sexos, na dimensão 'Estudo' do QVA-r, as mulheres tiveram médias significativamente maiores, indicando que as participantes do sexo feminino tendem a ser mais organizadas nas tarefas relativas ao estudo.

Com relação às análises por faixas etárias, os resultados indicaram que os participantes com mais de 
Tabela 6. Diferença de média e teste $t$ do curso de Direito EAP e QVA-r

\begin{tabular}{|c|c|c|c|c|c|c|}
\hline$E A P$ & Semestre & $N$ & Média & $D P$ & $t$ & $p$ \\
\hline \multirow[t]{2}{*}{ Ciências Exatas } & 1 & 39 & 31,64 & 10,78 & 0,68 & 0,499 \\
\hline & 10 & 35 & 29,85 & 11,78 & & \\
\hline \multirow[t]{2}{*}{ Artes e Comunicação } & 1 & 36 & 36,13 & 10,91 & $-0,13$ & 0,897 \\
\hline & 10 & 35 & 36,48 & 11,59 & & \\
\hline \multirow[t]{2}{*}{ Ciências Biológicas e da Saúde } & 1 & 39 & 23,15 & 9,79 & $-0,00$ & 0,993 \\
\hline & 10 & 35 & 23,17 & 8,52 & & \\
\hline \multirow[t]{2}{*}{ Ciências Agrárias e Ambientais } & 1 & 38 & 39,73 & 9,40 & $-0,99$ & 0,322 \\
\hline & 10 & 35 & 42,08 & 10,71 & & \\
\hline \multirow[t]{2}{*}{ Atividades Burocráticas } & 1 & 38 & 39,97 & 7,65 & $-0,47$ & 0,635 \\
\hline & 10 & 36 & 40,88 & 8,82 & & \\
\hline \multirow[t]{2}{*}{ Ciências Humanas e Sociais } & 1 & 37 & 32,86 & 6,54 & $-0,94$ & 0,348 \\
\hline & 10 & 34 & 34,17 & 4,95 & & \\
\hline \multirow[t]{2}{*}{ Entretenimento } & 1 & 39 & 15,20 & 6,20 & 0,12 & 0,901 \\
\hline & 10 & 36 & 15,02 & 6,12 & & \\
\hline \multicolumn{7}{|l|}{ QVA-r } \\
\hline \multirow[t]{2}{*}{ Pessoal } & 1 & 37 & 49,40 & 7,75 & $-1,37$ & 0,175 \\
\hline & 10 & 35 & 51,88 & 7,59 & & \\
\hline \multirow[t]{2}{*}{ Interpessoal } & 1 & 34 & 47,58 & 8,06 & $-1,88$ & 0,063 \\
\hline & 10 & 37 & 50,75 & 5,99 & & \\
\hline \multirow[t]{2}{*}{ Carreira } & 1 & 36 & 50,61 & 5,56 & 0,71 & 0,479 \\
\hline & 10 & 38 & 49,63 & 6,22 & & \\
\hline \multirow[t]{2}{*}{ Estudo } & 1 & 37 & 34,45 & 4,85 & 0,96 & 0,340 \\
\hline & 10 & 36 & 33,25 & 5,86 & & \\
\hline \multirow[t]{2}{*}{ Institucional } & 1 & 37 & 30,35 & 4,77 & 1,91 & 0,060 \\
\hline & 10 & 36 & 28,27 & 4,46 & & \\
\hline
\end{tabular}

Fonte: Elaboração dos autores.

26 anos obtiveram médias maiores do que os demais grupos na dimensão 'Carreira' do QVA, sugerindo que os estudantes dessa faixa tendem a vivenciar suas experiências acadêmicas de forma mais adaptada (Granado, 2004). Por outro lado, as menores médias foram obtidas pelo grupo etário intermediário (entre 19 e 26 anos), sendo que o grupo com idade inferior a 19 anos não se diferenciou dos grupos inferior e superior.

Esses resultados podem sugerir que o grupo inferior aos 19 anos talvez seja formado predominantemente por alunos ingressantes, que ainda não tenham base para avaliar suas vivências, uma vez que suas experiências acadêmicas ainda são restritas (Soares \& Almeida, 2002). Com relação ao grupo intermediário, percebe-se que este abrange uma faixa etária diversificada, condensando sujeitos que talvez já tenham tido experiências anteriores e outros que não, havendo assim uma diversificação dos escores no QVA-r.

Entretanto, as análises relativas aos semestres cursados indicaram que não houve diferenças entre estudantes ingressantes e concluintes, tanto com relação aos interesses quanto às vivências acadêmicas, em nenhum dos cursos. Assim, pode-se hipotetizar que as diferenças na percepção das vivências relativas à dimensão 'Carreira' parecem estar relacionada à idade e não ao semestre cursado, sugerindo que a preocupação com o sucesso na carreira seja uma questão etária e não necessariamente atrelada ao semestre cursado (Soares \& Almeida, 2002).

Ainda pode-se dizer que os resultados indicaram que os cursos, especialmente Administração, tenderam a optar por atividades profissionais típicas de seus cursos, corroborando os achados de Noronha e colaboradores (2007) e Noronha e Ambiel (no prelo). Assim, observa-se que a preferência dos estudantes do curso de Administração foi significativamente maior nas dimensões 'Ciências Exatas', 'Atividades Burocráticas' e 'Entretenimento'.

Vale destacar que os itens que compõem essa última dimensão dizem respeito basicamente a atividades relativas à implementação e ao gerenciamento de unidades de lazer, tais como parques, hotéis e clubes. Entretanto, observa-se a necessidade de uma investigação mais pormenorizada sobre as preferências dos estudantes de Direito dessa amostra por atividades das dimensões 'Ciências Biológicas e da Saúde' e 'Ciências Agrárias e Ambientais', uma vez que esses achados vão de encontro aos de Noronha e cols. (2007). 
Tabela 7. Correlações entre as dimensões da EAP e do QVA-r

\begin{tabular}{|c|c|c|c|c|c|c|}
\hline & & Pessoal & Interpessoal & Carreira & Estudo & Institucional \\
\hline \multirow[t]{2}{*}{ Ciências Exatas } & $r$ & $-0,13$ & $-0,12$ & $-0,09$ & $-0,07$ & $-0,15$ \\
\hline & $p$ & 0,118 & 0,131 & 0,268 & 0,379 & 0,070 \\
\hline \multirow[t]{2}{*}{ Artes e Comunicação } & $r$ & $-0,09$ & 0,16 & 0,10 & 0,00 & $-0,14$ \\
\hline & $p$ & 0,273 & 0,049 & 0,230 & 0,946 & 0,102 \\
\hline \multirow{2}{*}{$\begin{array}{l}\text { Ciências Biológicas e da } \\
\text { Saúde }\end{array}$} & $r$ & $-0,12$ & $-0,02$ & $-0,09$ & $-0,01$ & $-0,31$ \\
\hline & $p$ & 0,137 & 0,787 & 0,254 & 0,873 & 0,000 \\
\hline \multirow{2}{*}{$\begin{array}{l}\text { Ciências Agrárias e } \\
\text { Ambientais }\end{array}$} & $r$ & $-0,13$ & 0,16 & 0,01 & 0,08 & $-0,23$ \\
\hline & $p$ & 0,111 & 0,048 & 0,845 & 0,323 & 0,004 \\
\hline \multirow[t]{2}{*}{ Atividades Burocráticas } & $r$ & 0,13 & 0,08 & 0,18 & 0,31 & 0,14 \\
\hline & $p$ & 0,121 & 0,306 & 0,031 & 0,000 & 0,086 \\
\hline \multirow[t]{2}{*}{ Ciências Humanas e Sociais } & $r$ & $-0,02$ & 0,16 & 0,27 & 0,20 & $-0,02$ \\
\hline & $p$ & 0,793 & 0,063 & 0,001 & 0,014 & 0,817 \\
\hline \multirow[t]{2}{*}{ Entretenimento } & $r$ & 0,02 & 0,01 & 0,00 & $-0,03$ & 0,16 \\
\hline & $p$ & 0,754 & 0,841 & 0,930 & 0,711 & 0,053 \\
\hline
\end{tabular}

Fonte: Elaboração dos autores.

Com relação ao QVA-r, observou-se que os cursos se diferenciaram nas dimensões 'Interpessoal' e 'Carreira', com maiores médias para Direito, e 'Institucional', com destaque para Administração. Assim, pode-se dizer que os estudantes de Direito têm relações interpessoais mais satisfatórias no ambiente acadêmico, bem como se sentem mais adaptados à carreira escolhida. Por outro lado, os estudantes de Administração relatam maior satisfação com a instituição de ensino, tanto estrutural, quanto afetivamente (Granado, 2004).

No que diz respeito às correlações, 'Artes e Comunicação'relacionou-sepositivamentecom'Interpessoal'. O relacionamento com colegas e estabelecimento de amizades, aspectos referentes à dimensão 'Interpessoal' do QVA-r, podem estar presentes em pessoas com interesse em 'Artes e Comunicação', uma vez que estas tendem a gostar de atividades envolvidas com o público.

Como observado, a dimensão 'Ciências Biológicas e da Saúde' obteve correlação negativa com a dimensão 'Institucional'. Pode-se supor que os estudantes mais adaptados à instituição que frequentam escolhem menos atividades dessa dimensão, o que parece estar em concordância com os achados de Noronha e cols. (2007), uma vez que os estudantes de Administração e Direito possuem pouco interesse nessa área, 'Ciências Biológicas e da Saúde'.
Em relação à correlação positiva entre 'Ciências Agrárias e Ambientais' e 'Interpessoal', pode-se dizer que os estudantes avaliados possuem preferências por atividades profissionais relativas ao campo, à agricultura, ao meio ambiente e à saúde. Faz-se necessário ressaltar que, de acordo com Noronha e cols. (2007), as pessoas podem escolher atividades que não estão diretamente ligadas a seu curso. Além disso, supõe-se que esses estudantes têm boa relação entre seus pares, com um lado mais social ou interpessoal, que caracteriza pessoas com interesse em 'Ciências Agrárias e Ambientais'. Por outro lado, os alunos de Administração e Direito, avaliados no presente estudo, demonstram estar pouco adaptados e insatisfeitos com a infra-estrutura da instituição e as suas atividades extracurriculares, levando a acreditar que a instituição possui certa carência nos aspectos relacionados à preservação ecológica e da saúde.

De acordo com Noronha e cols. (2007), a maioria das pessoas dos cursos de Direito e Administração tem preferência por atividades burocráticas. Nesse sentido, a correlação positiva entre 'Atividades Burocráticas' e as dimensões 'Carreira' e 'Estudo' do QVA-r evidencia que os estudantes, por possuírem interesse por esta área, dedicamse aos seus projetos profissionais e ao desenvolvimento de sua carreira. Além disso, apresentam organização referente aos métodos de estudo, gestão do tempo, utilização da 
biblioteca e outros recursos de aprendizagem. A correlação positiva entre 'Ciências Humanas e Sociais Aplicadas' e as dimensões 'Carreira' e 'Estudo' permite evidenciar que os estudantes apresentam preferência por atividades dessa área, o que faz com que estes planejem sua futura carreira, esforçando-se em relação à adaptação ao curso, aos estudos e às situações do quotidiano de trabalho.

Por fim, a dimensão 'Entretenimento' obteve correlação positiva com 'Institucional'. Dessa forma, podese dizer que os estudantes mais satisfeitos com a instituição que frequentam preferem atividades extracurriculares relacionadas ao entretenimento.

\section{Considerações Finais}

A partir dos dados encontrados, constatou-se que os construtos interesse e vivência acadêmica possuem relações tanto positivas quanto negativas, de modo que se pode inferir que os interesses profissionais estão associados às experiências vivenciadas na universidade. Estes achados contribuem para a área de orientação profissional e desenvolvimento de carreira, na qual existem poucos estudos a respeito da relação entre os construtos avaliados, bem como pesquisas com a população universitária.

No que se refere à amostra estudada, constatouse que não houve diferenças entre os períodos iniciais e finais do curso em relação aos construtos pesquisados, porém nota-se diferença em relação à faixa etária (vivência acadêmica), suscitando a necessidade de futuras pesquisas acerca destes achados. Em relação aos cursos, faz-se necessária maior investigação no que diz respeito às preferências dos estudantes de Direito, que se interessaram por atividades das dimensões 'Ciências Biológicas e da Saúde' e 'Ciências Agrárias e Ambientais'. Entretanto, estes achados são coerentes com a teoria da Escala de Aconselhamento Profissional, na qual as preferências por atividades profissionais podem não ser somente pela área escolhida, mas pelas variadas opções de carreiras que o indivíduo de um mesmo curso pode seguir.

Salienta-se, portanto, a necessidade de estudos que investiguem a relação entre os construtos, bem como os cursos investigados, possibilitando maior conhecimento a respeito desta fase em que pode haver dúvidas em relação ao curso escolhido e ao planejamento de carreira.

\section{Referências}

Almeida, L. S., Soares, A. P. C., \& Ferreira, J. A. (2002). Questionário de Vivências Acadêmicas (QVA-r): Avaliação do ajustamento dos estudantes universitários. Avaliação Psicológica, 2(1), 81-93.

Bordin, E. G. (1943). A theory of interests as dynamic phenomena. Educational and Psychological Measurement, 3, 49-66.

Carter, H. D. (1940). The development of vocational attitudes. Journal of Consulting Psychology, 4, 185-191.
Cunha, S. M., \& Carrilho, D. M. (2005). O processo de adaptação ao ensino superior e o rendimento acadêmico. Psicologia escolar e educacional (9)2, 215-224.

Granado, J. I. F. (2004). Vivência acadêmica de universitários brasileiros: estudo de validade e precisão do QVA-r. Dissertação de Mestrado, Programa de Pós-Graduação Stricto Sensu em Psicologia, Universidade São Francisco, Itatiba, São Paulo.

Holland, J. L. (1963). Explorations of a theory of vocational choice: II a four year prediction study. Psychological Reports, 12(2), 547549.

Lent, R. W., Hackett, G., \& Brown, S. D. (1994). Toward a unifying social cognitive theory of career and academic interest, choice, and performance. Journal of Vocational Behavior, 45, 79-122.

Mattiazzi, B. (1977). A Natureza dos Interesses e a Orientação Vocacional. Petrópolis, RJ: Vozes.

Melo-Silva, L. L. (1999). A formação do orientador profissional. Revista da $A B O P, 3(1)$, 161-165.

Melo-Silva, L. L., Noce, M. A., \& Andrade, P. P. (2003). Interesses em adolescentes que procuram orientação profissional. Psic: Revista de Psicologia da Vetor Editora, 4(2), 6-17.

Noronha, A. P. P., \& Ambiel, R. A. M. (2006). Orientação profissional e vocacional: análise da produção científica. Psico-USF, 11(1), 75-84.

Noronha, A. P. P., \& Ambiel, R. A. M. (no prelo). Interesses profissionais: um estudo correlacional entre EAP e SDS. Interação em Psicologia.

Noronha, A. P. P., Sisto, F. F., \& Santos, A. A. A. (2007). Escala de Aconselhamento Profissional - EAP Manual de Aplicação. São Paulo: Vetor.

Okino, E. T. K., Noce, M. A., Assoni, R. F., Corlatti, C. T., Pasian, S. R., \& Jacquemin, A. (2003). A adaptação do BBT - Teste de Fotos de Profissões - para o contexto sociocultural brasileiro. Revista Brasileira de Orientação Profissional, 4(1/2), 87-96.

Santos, A. A. A., Noronha, A. P. P., Amaro, C. B., \& Villar, J. (2005). Questionário de Vivência Acadêmica: estudo de consistência interna do instrumento no contexto brasileiro. Em M. C. R. A. Joly., A. A. A dos Santos, \& F. F. Sisto (Orgs.), Questões do cotidiano universitário (pp. 159-177). São Paulo: Casa do Psicólogo.

Sartori, F. A. (2007). Estudo Correlacional entre a Escala de Aconselhamento Profissional (EAP) e o Self- Directed Search Career Explorer (SDS). Dissertação de Mestrado, Programa de Pós-Graduação Stricto Sensu em Psicologia, Universidade São Francisco, Itatiba, São Paulo.

Savickas, M. L. (1995). Examining the Personal Meaning of Inventoried Interests During Career Counseling. Journal of Career Assessment, 3(2), 188-201.

Soares, A. P. C., \& Almeida, L. S. (2002). Expectativas acadêmicas e adaptação à universidade: um estudo com alunos do $1^{\circ}$ ano da Universidade do Minho. Em IV Seminário Investigação e Intervenção psicológica no ensino superior. Recuperado: 29 abr. 2008. Disponível: http://www.fchs.ualg.pt/ceduc/fases/2/ comunicacoes/leandroalmeida.htm. Acesso em 29 de abril de 2008.

Tyler, L. E. (1951). The relationship of interests to abilities and regulation among firstgrade. Psychological Measurement, 3, 4966.

Vendramini, C. M. M., Santos, A. A. A., Polydoro, S. A. J., Sbardelini, E. T. B., Serpa, M. N. F., \& Natário, E. G. (2004). Construção e validação de uma escala sobre avaliação da vida acadêmica (EAVA). Estudos de Psicologia, 9(2), 259-268. 
Welter, G. M. R. (2007). O BBT - Teste de Fotos de Profissões em Adultos e Adolescentes. Revista Brasileira de Orientação Profissional, 8(1), 45-58.

Recebido em: 02/07/2008

Reformulado em: 20/07/2009

Aprovado em: 26/07/2009

\section{Sobre os autores}

Ana Paula Porto Noronha

Doutora em Psicologia e Docente do Programa de Pós-Graduação em Psicologia da Universidade São Francisco.

Denise da Fonseca Martins

Psicóloga e Mestranda do Programa de Pós-Graduação em Psicologia da Universidade São Francisco.

Marina Gasparoto do Amaral Gurgel

Mestranda do Programa de Pós-Graduação em Psicologia da Universidade São Francisco.

Rodolfo Augusto Matteo Ambiel

Mestrando do Programa de Pós-Graduação em Psicologia da Universidade São Francisco. . 